RFP-2304

RFP-2304

August 22, 1974

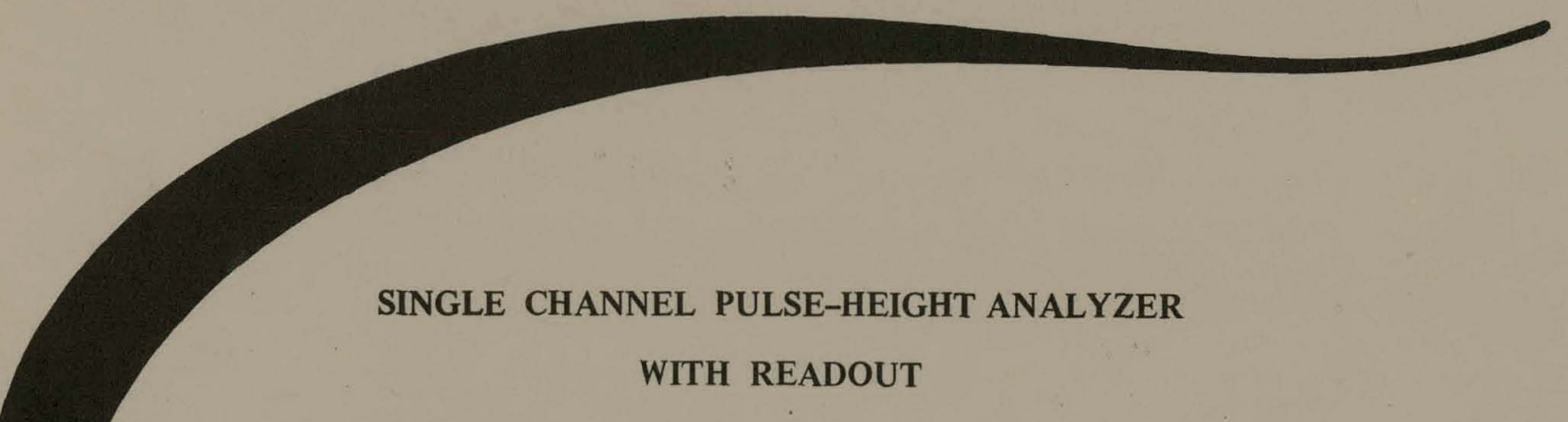

Bradley E. Martin

Modules for Radiation Detection Systems and related items will be grouped in a series of reports beginning with RFP-2300 through RFP-2325. RFP-2304 represents a continuation in the series.

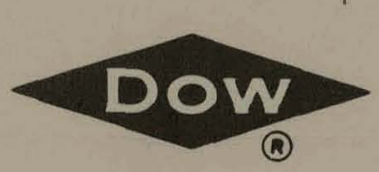

DOW CHEMICAL U.S.A.

ROCKY FLATS DIVISION

P. O. BOX 888

GOLDEN, COLORADO 80401

U. S. ATOMIC ENERGY COMMISSION CONTRACT AT(29-1)-1106 


\section{DISCLAIMER}

This report was prepared as an account of work sponsored by an agency of the United States Government. Neither the United States Government nor any agency Thereof, nor any of their employees, makes any warranty, express or implied, or assumes any legal liability or responsibility for the accuracy, completeness, or usefulness of any information, apparatus, product, or process disclosed, or represents that its use would not infringe privately owned rights. Reference herein to any specific commercial product, process, or service by trade name, trademark, manufacturer, or otherwise does not necessarily constitute or imply its endorsement, recommendation, or favoring by the United States Government or any agency thereof. The views and opinions of authors expressed herein do not necessarily state or reflect those of the United States Government or any agency thereof. 


\section{DISCLAIMER}

Portions of this document may be illegible in electronic image products. Images are produced from the best available original document. 


\section{LEGAL NOTICE}

This report was prepared as an account of work sponsored by the United States Government. Neither the United States nor the United States Atomic Energy Commission, nor any of their employees, nor any of their contractors, subcontractors, or their employees, makes any warranty, expressed or implied, or assumes any legal liability or responsibility for the accuracy, completeness or usefulness of any information, apparatus, product or process disclosed, or represents that its use would not infringe privately owned rights.

Printed in the United States of America

Available from the

National Technical Information Service

U. S. Department of Commerce Springfield, Virginia 22151

Price: Printed Copy $\$ 4.00$ Microfiche $\$ 1.45$ 


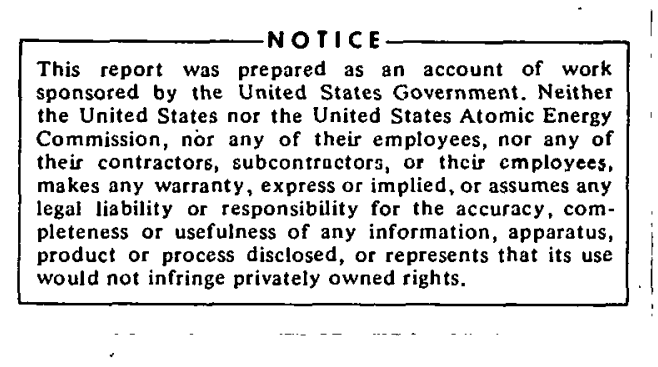

\title{
SINGLE CHANNEL PULSE-HEIGHT ANALYZER WITH READOUT
}

\author{
Bradley E. Martin
}

Product and Health Physics Research

ELECTRONICS GROUP

Modules for Radiation Detection Systems and related items will be grouped in a series of reports beginning with RFP-2300 through RFP-2325. RFP-2304 represents a continuation in the series.

\section{SUBJECT DESCRIPTORS}

Single Channel Pulse-Helght Analyzers

Wound Counting Systems

Gamma Spectrometers

Electronics

Monitoring Systems

Nuclear Instrumentation Bin

DOW CHEMICAL U.S.A.

ROCKY FLATS DIVISION

P. O. BOX 888

GOLDEN, COLORADO 80401

Prepared under Contract AT(29-1)-1106

for the

Albuquerque Operations Office

U. S. Atomic Energy Commission 


\section{CONTENTS}

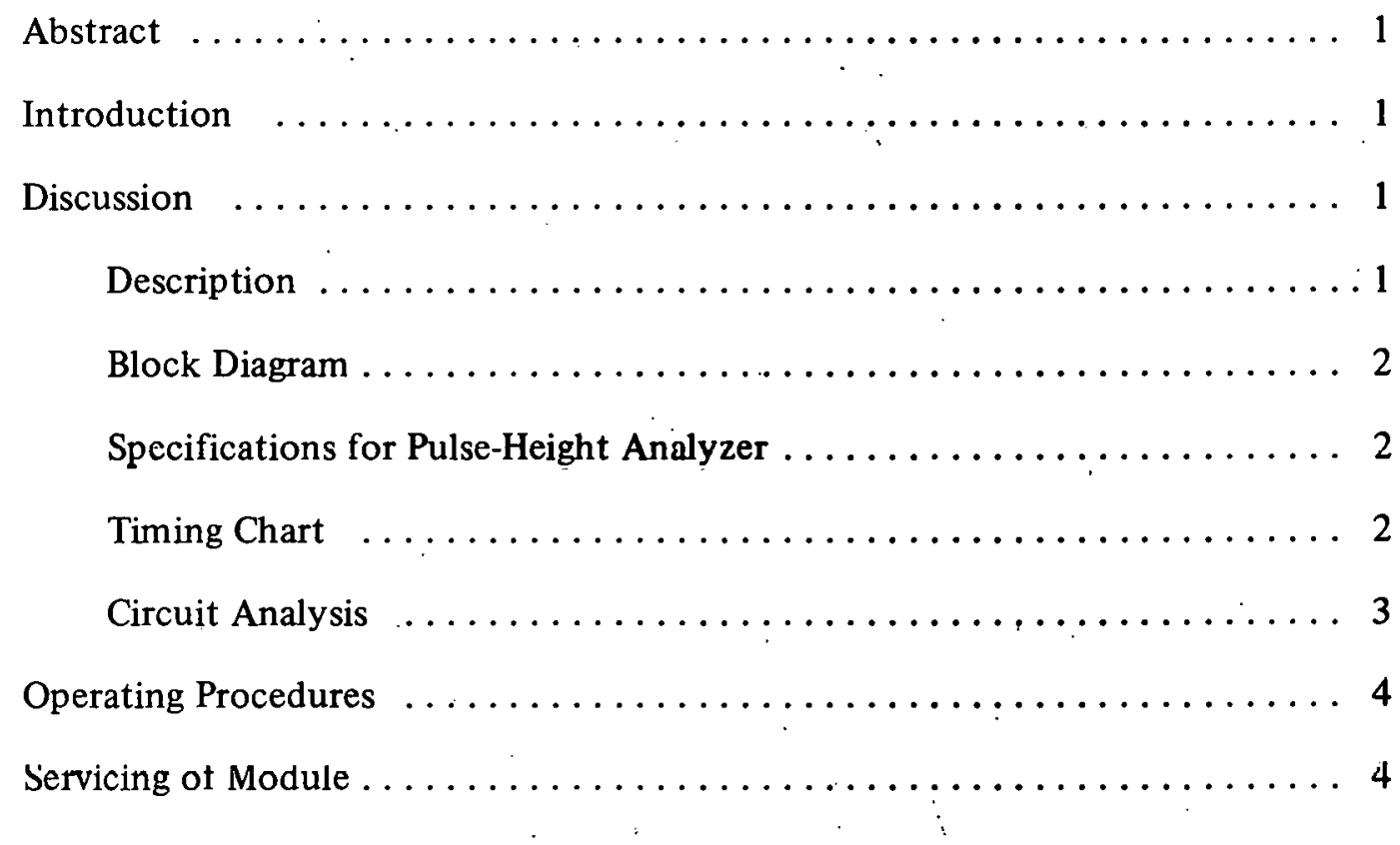


RFP-2304

\title{
SINGLE CHANNEL PULSE-HEIGHT ANALYZER \\ WITH READOUT
}

\author{
Bradley E. Martin
}

\begin{abstract}
In developing radiation-detection instrumentation at Rocky Flats Division, a system concept using plug-in modules was planned. Losses of operational time due to maintenance are drastically reduced as a malfunctioning module can be replaced within minutes. Versatility is another advantage of the modular concept. A particular module can be used in many different system designs: A significant cost savings in system development can also be realized.
\end{abstract}

The single channel pulse-height analyzer described is housed in a one-wide Nuclear Instrumentation Bin (NIM-BIN) module. The design uses the latest COS/MOS (complementary symmetry metal-oxide semiconductor) integrated circuits (IC) featuring low power, low cost, and high reliability. The module was developed specifically for isotopic identity in radiation-detection systems.

\section{INTRODUCTION}

The single channel analyzer (SCA) with readout module is described. Model 27213-42 was developed for isotopic identification in radiationdetection systems. Low power consumption makes the model ideal for battery-operated instrumentation.

The SCA has importance in determining the level of contamination for a particular isotope. Under the Health Physics monitoring program at Rocky Flats Plant, concerted efforts are directed towards improvements in safety, state-of-the-art applicalions, and the reduction of operating costs.

\section{DISCUSSION}

Description:

Model $27213-42$ is a single channel pulse-height analyzer with a scaler and readout located in the same package.

The SCA consists of two integral discriminators that are set to different levels. Signals occurring between these settings produce an output pulse. Those signals above the upper level and below the lower-level settings do not generate any output. The output from the SCA is applied to the scaler which counts up and stores the pulses. The readout is continuously available at the front panel if the display switch remains in the normal position. The display may be left in the $O F F$ position and the push-to-read feature be used to conserve power (an advantage in battery-operated systems).

The complete module appears in Figure 1.* Figure 2 is an interior view of the module and shows the three printed circuit boards (PCB): the $S C A-P C B$, the scaler $P C B$, and the readout PCB.

The SCA-PCB uses four COS/MOS ICs and one transistor. The power requires +12 volts at 2 milliamperes. The input impedance is $1 \mathrm{~K}$ ohms $(\mathrm{K}=1000)$ and the output impedance is 50 ohms.

The scaler PCB uses six COS/MOS IC decade-divider counters and six bipolar IC-transistor arrays as current boosters for the COS/MOS ICs.

\footnotetext{
* Illustrations follow at ond of text.
} 
The MAN-64A seven-segment light-emitting diode (LED) displays are located on the readout PCB. The readout PCB joins to the scaler PCB at a right angle by a unique connector. The connector eliminates the massive cable harness, common to many such units.

The scaler and readout assembly and the SCA-PCB are mounted to the right-side rails of the module case. All circuitry is accessible for easy maintenance.

The front panel features a black magic type display, made of red-translucent plastic. The back side of the panel is painted flat-black, with exception of the LED viewing area. Normally, the panel appears dark, but when the LEDs are illuminated, they show through the plastic and provide a clear, eyepleasing display.

The rear panel (Figure 3) shows the upper- and lower-level discriminator controls and the SCA input and output receptacles. The NIM-BIN connector routes power and control functions intu the mudule.

\section{Block Diagram:}

Figure 4 shows the SCA $\bar{M}$ odel $27213-42$. Pin 26 of the NIM-BIN connector supplies 2.5 volts AC to the readout PCB through S1. The switch (S1) provides a continuous display in the normal mode and a momentary display in the push-toread position.

Pin 27 of the NIM-BIN connector delivers +5 volts DC to the scaler PCB and Pin 16 provides +12 volts DC to the SCA-PCB. The reset from Pin 24 and the enable from Pin 22 are control inputs to the scaler PCB. The SCA-PCB receives signals from the SCA input receptacle and processes them in accordance with the settings of the upper level discriminator (ULD) and the lower level discriminator (LLD). The signals falling between these settings produce an output to Terminal 1 of the scaler PCB and to the SCA output receptacle.
The scaler counts up and stores the output pulses produced by the SCA and the readout displays the number of pulses counted.

Specifications for Pulse-Height Analyzer:

Input Signal Requirements:

\begin{tabular}{|c|c|c|}
\hline Shape & - & Unipolar or Bipolar \\
\hline Polarity & - & Positive \\
\hline Amplitude & - & 0.5 to 10 volts \\
\hline Input Impe & & $1 \mathrm{~K}$ ohms \\
\hline
\end{tabular}

Output Signal Characteristics:

\begin{tabular}{|c|c|c|}
\hline Shape & - & Rectangular \\
\hline Polarity & - & Positive \\
\hline Amplitude & - & $\begin{array}{l}8 \text { volts, open circuit } \\
4 \text { volts, sU-ohm termina- } \\
\text { tion }\end{array}$ \\
\hline Width & - & 1 microsecond \\
\hline Rise Time & - & 30 nanoseconds \\
\hline Fall Time & - & 100 nanoseconds \\
\hline $\begin{array}{l}\text { Output } \\
\text { Impedance }\end{array}$ & - & 50 ohms \\
\hline $\begin{array}{l}\text { Power } \\
\text { Requirements }\end{array}$ & - & $\begin{array}{l}+12 \text { volts } \mathrm{DC} \text { at } 2 \\
\text { milliamperes }\end{array}$ \\
\hline
\end{tabular}

\section{Timing Chart:}

Figure 5 shows a timing chart and a logic diagram of the pulse-height SCA. The input signal is applied through the threshold control circuitry to $\mathrm{Al}$, the ULD, and to A2, the LLD. If the input signal exceeds the threshold setting of $\mathrm{A} 2$, then A2 produces a two-microsecond pulse. 
The pulse is differentiated and the trailing edge is used to trigger $\mathrm{A} 3$, the inhibit, and $\mathrm{A} 4$, the gate. A one-microsecond output pulse is generated by A4. If the input signal also exceeded the threshold setting of $\mathrm{Al}$, then $\mathrm{Al}$ produces a four-microsecond pulse which couples to A4 as a disable and stops A4 from generating an output. The inhibit circuit, A3, produces an 8-microsecond pulse which keeps $\mathrm{A} 1$ and $\mathrm{A} 2$ from being retriggered. Transistor $\mathrm{Q} 1$ is an emitter-follower circuit that provides a $50-0 h m$ output impedance.

\section{Circuit Analysis:}

Figure 6 shows a schematic diagram of the SCAPCB. The input signal from the jack (J1) is divided-by-four by resistors $\mathrm{R} 1$ and $\mathrm{R} 2$ and coupled to A2 through the capacitor, $\mathrm{C} 4$, and to A1 through C.3. The trigger threshold (TT) of $\mathrm{A} 1$ is determined by R5, R6, and R-ULD, and the TT of A2 is determined by R3, R4, and R-LLD. Knobpots R-ULD and R-LLD, located on the rear panel, are the adjustable discriminator controls for the unit. Trimpots R3 and R5 (resistors) are set at initial calibration and should not be adjusted except when IC replacement makes recalibration necessary.

Components $\mathrm{C} 7$ and $\mathrm{R} 13$ determine the twomicrosecond pulse width from $\mathrm{A} 2$ and $\mathrm{C} 8$ and $\mathrm{R} 14$ determine the four-microsecond pulse width from A1. The pulse from Pin 11 of A2 is differentiated by $C 9, R 11$, and $L 1$. Diode D1 shunts the negative spike to ground and dampens the oscillalions caused by $\mathrm{L} 1$. The positive pulse representing the trailing edge of the pulse from Pin 11 is used as a trigger for A3 and A4. The pulse from Pin 10 of A1 is coupled to Pin 6 of A4 as a disable.

Circuit A4 functions as a gate. If the trigger is applied without the disable, then A4 produces a one-microsecond pulse at Pin 10. Component C5 and $\mathrm{R} 10$ determine the pulse width at Pin 10 of A4. If no trigger is applied or if the trigger and the disable are both applied, then A4 will not generate an output. The inhibit circuit, A3, is triggered by A2. An 8-microsecond output pulse is determined by C6 and R12. This pulse acts as an inhibit to Al and A2 and keeps them from being retriggered during the processing of a signal. A 50-ohm output impedance is established by the transistor (Q1), R7, R8, and R9. Proper filtering for COS/MOS circuitry is provided by $\mathrm{C} 1$ and $\mathrm{C} 2$. Figure 7 is a component layout for SCA-PCB.

Figure 8 shows a schematic diagram of the scaler PCB. Output pulses from the SCA-PCB are applied to Terminal 1. The scaler PCB, 320-01014, is used in other modules. In this application, Al is not used and a jumper wire is placed between Pin 5 and Pin 6 of the A1 position. This couples the input pulses from R1, D1 to Pin 1 of A2. Approximately three volts are necessary to trigger A2. In order to protect the internal circuitry of $A 2, R 1$, and D1, limit the maximum voltage at Pin 1 of $A 2$ to 4.7 volts.

A six-decade ripple counter is formed by $\mathrm{A} 2$ through $A 7$ providing a maximum counting range of 999,999 . The decade counters used are COS/MOS CD-4033 AE ICs, with decoded sevensegment display outputs and zero-blanking. Pin 3 of $A 2$ is the zero-blanking output and it connects to Pin 4 of A3. The zero-blanking function keeps the readout from displaying nonsignificant zeros. Pin 5 of A2 is the carry-out and connects to Pin 1 of A3. It provides one output pulse for every ten input pulses. Only the first decade of counting is shown for simplicity as the other five are typical. Pin 2 of A2 is the enable input and Pin 15 is the reset input.

Since the lamp-test function is performed in conjunction with the reset function, Pin 14 of A2 which is the lamp-test input is connected to the reset input.

The decoded seven-segment outputs from A2 are fed to A8. Similarly, the outputs from A3 are coupled to A9. This is typical for all decades. Integrated circuits $\mathrm{A} 8$ through $\mathrm{A} 13$ are transistor arrays which provide the necessary drive current for displaying the MAN-64As. The letters A through $G$ represent the MAN-64A segments. Capacitors $\mathrm{Cl}$ and $\mathrm{C} 4$ provide proper filtering as recommended for COS/MOS circuitry. 
Figure 9 shows a component layout for the scaler and readout PC boards. A pin description for the $\mathrm{M} \Lambda \mathrm{N}-64 \mathrm{~A}$ is also given.

\section{OPERATING PROCEDURES}

The following requirements and procedures are recommended when using the single channel pulse-height analyzer.

1. Plug SCA module in NIM BIN.

a. Power requirements:
(1) +12 volts, DC, Pin 16
(2) +5 volts, DC, Pin 27
(3) 2.5 volts, AC, Pin 26

b. Control requirements:
(1) Reset, Pin 22 (normally low, zcro volts)
(2) Enable, Pin 24 (normally high, +5 volts)

2. Connect input signal to the SCA input jack on rear of panel. (Input impedance is $1 \mathrm{~K}$ ohms.)

3. Turn on NIM-BIN power.

4. Adjust the LLD control to eliminate the signals that occur below the energy band of interest.

5. Adjust the ULD control to eliminate the signals that occur above the energy band of interest.

6. Place the display switch in the NORMAL mode for continuous readout or in the PRESS-TO-READ mode for momentary readout. (The press-to-read mode conserves power in battery-operated systems.)

7. The SCA is teady for operation.

\section{SERVICING OF MODULE}

The chart is included as a troubleshooting guide to assist in the performance of unscheduled maintenance.

$\begin{array}{cc}\text { Problem } & \text { Cause } \\ \text { No SCA output } & \text { 1. Faulty A3 } \\ \text { 2. Faulty A2 } \\ \text { 3. Faulty Q1 }\end{array}$

No LLD Control

1. Faulty A2

No ULD Control

1. Faulty A1

No lamp test

No reset

One or more MAN-64A segments do not light with lamp test

Does not count during the enable interval

Counts continuously when disabled
1. No 2.5 volts, AC.

2. No +5 volts, DC

3. Short on reset line (futuliy C.D-4033AF)

1. Burned out segment of MAN-64A

2. Faulty CA3081

3. Faulty CD-4033 AE

1. Faulty CD-4033AE

1. Short on enable line (faulty CD-4033AE) 


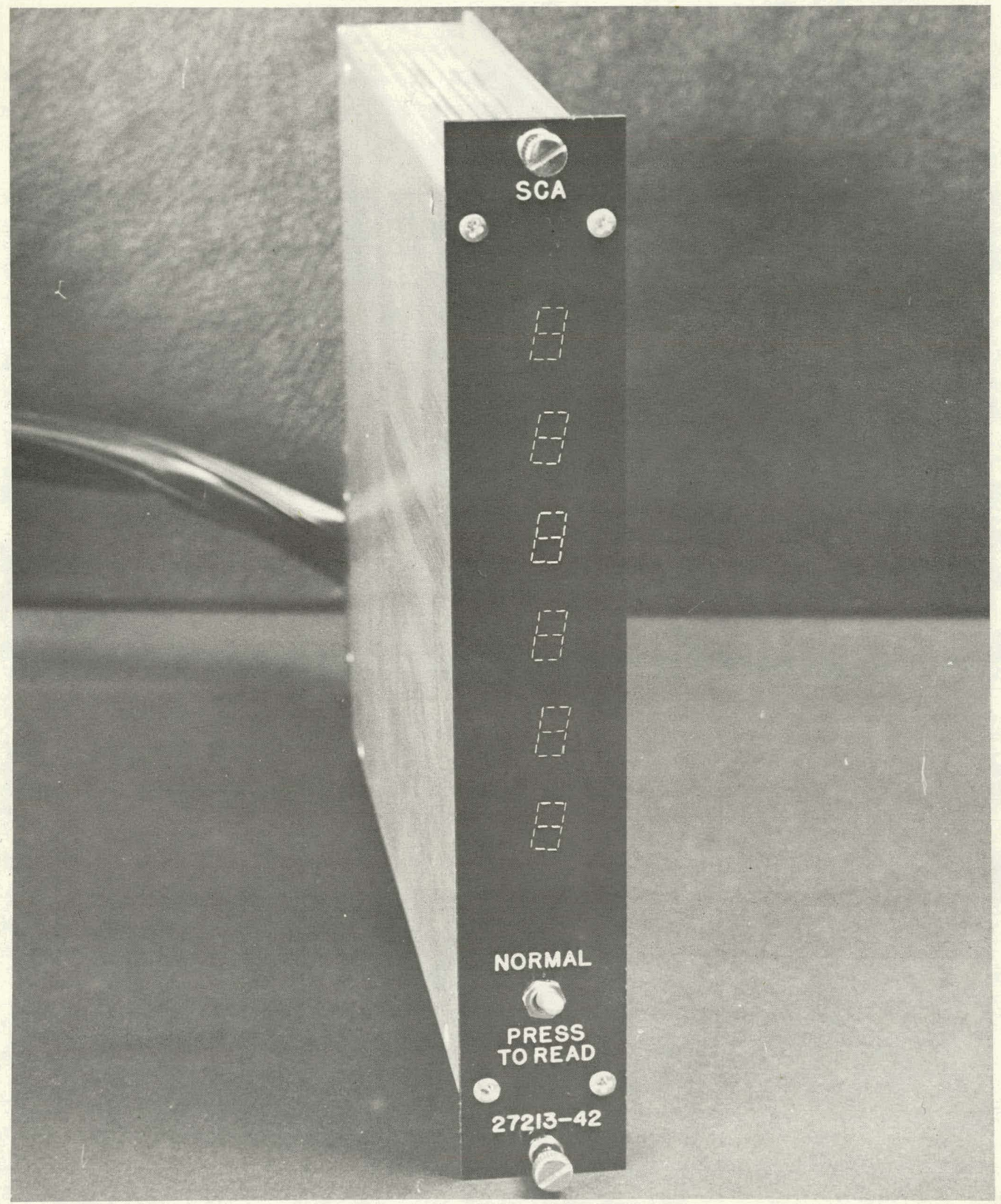

17700-1

FIGURE 1. Front View of Pulse Height Single Channel Analyzer. 


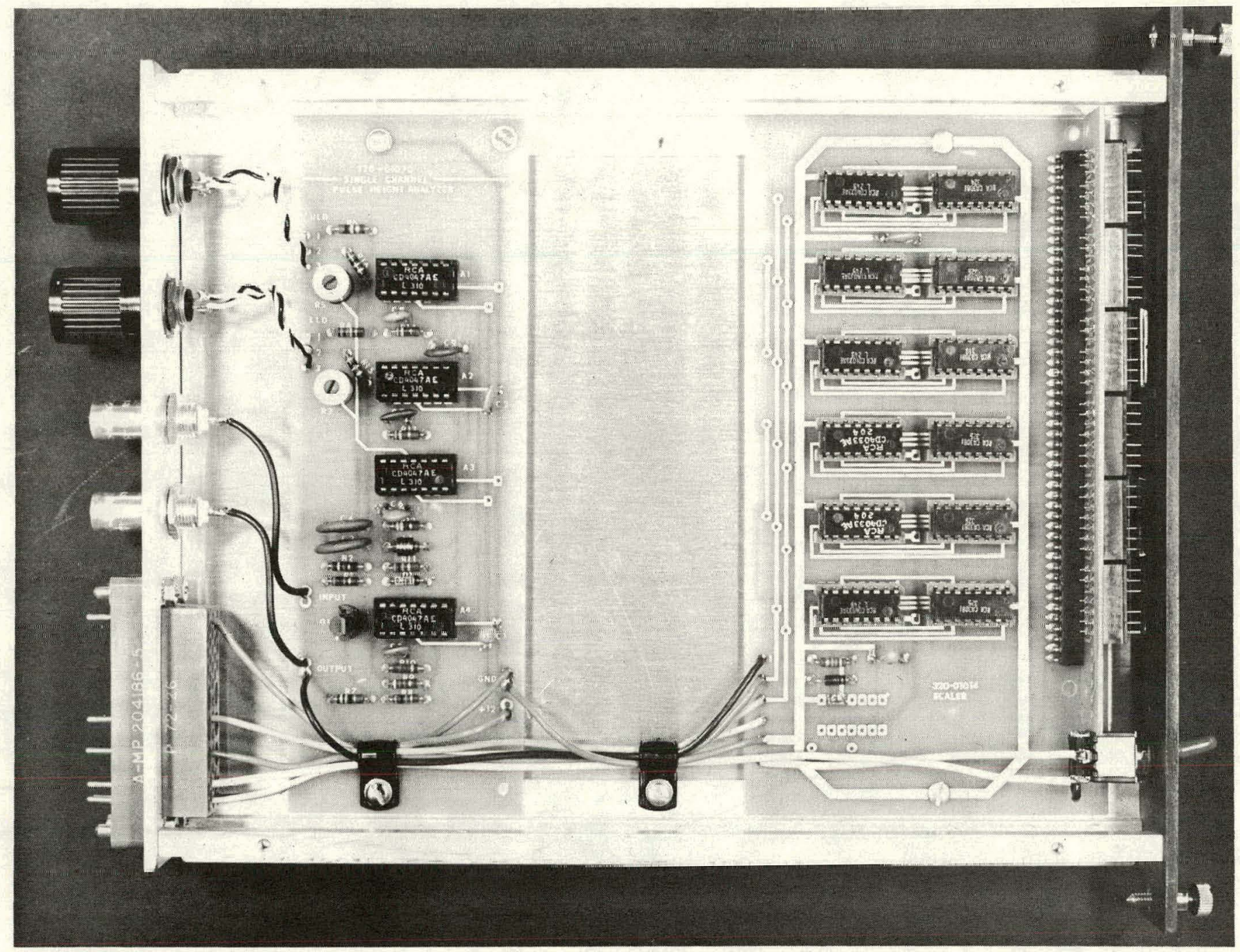

18778-6

FIGURE 2. Interior View of Pulse Height Single Channel Analyzer. 


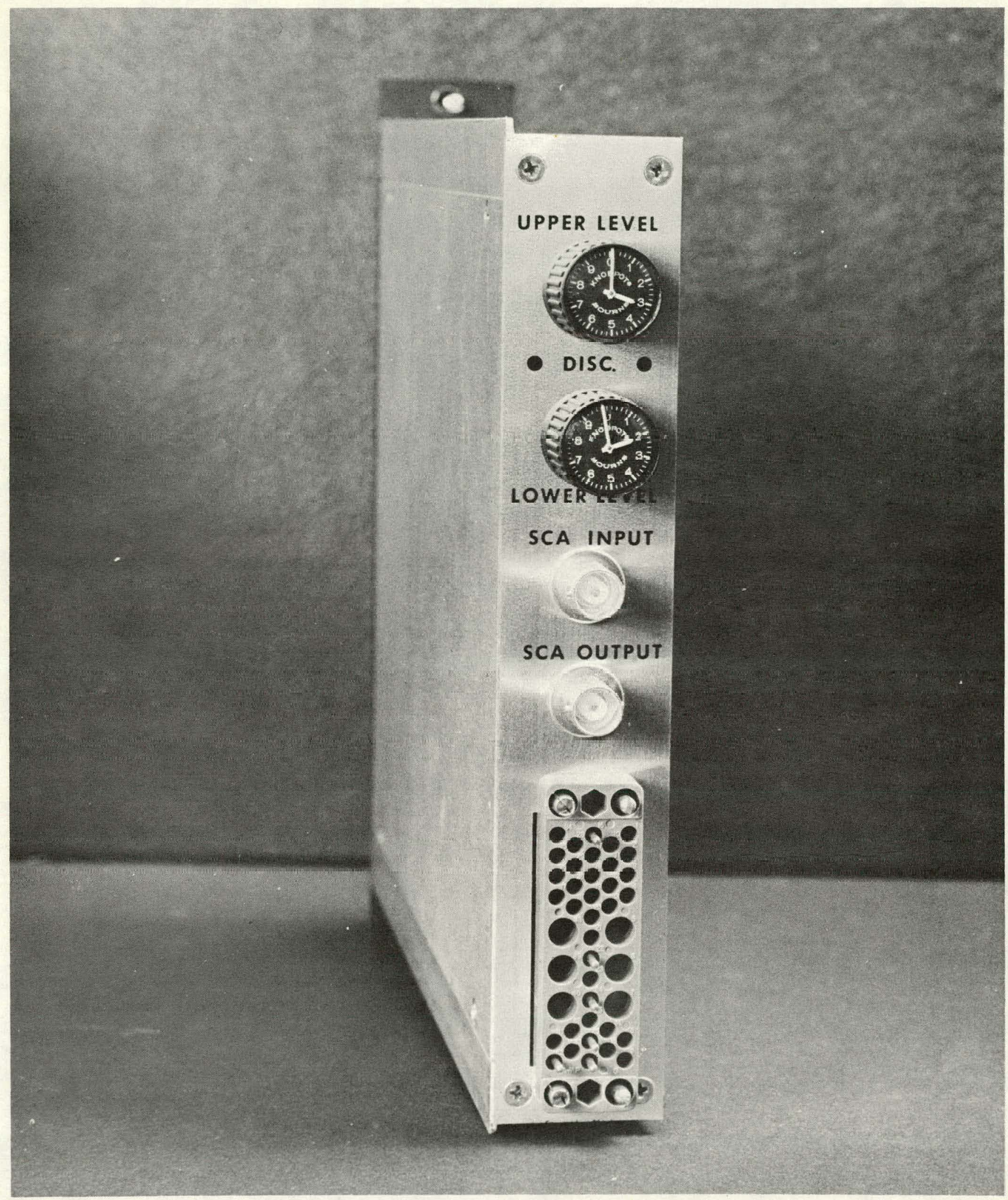

FIGURE 3. Rear View of Pulse Height Single Channel Analyzer. 


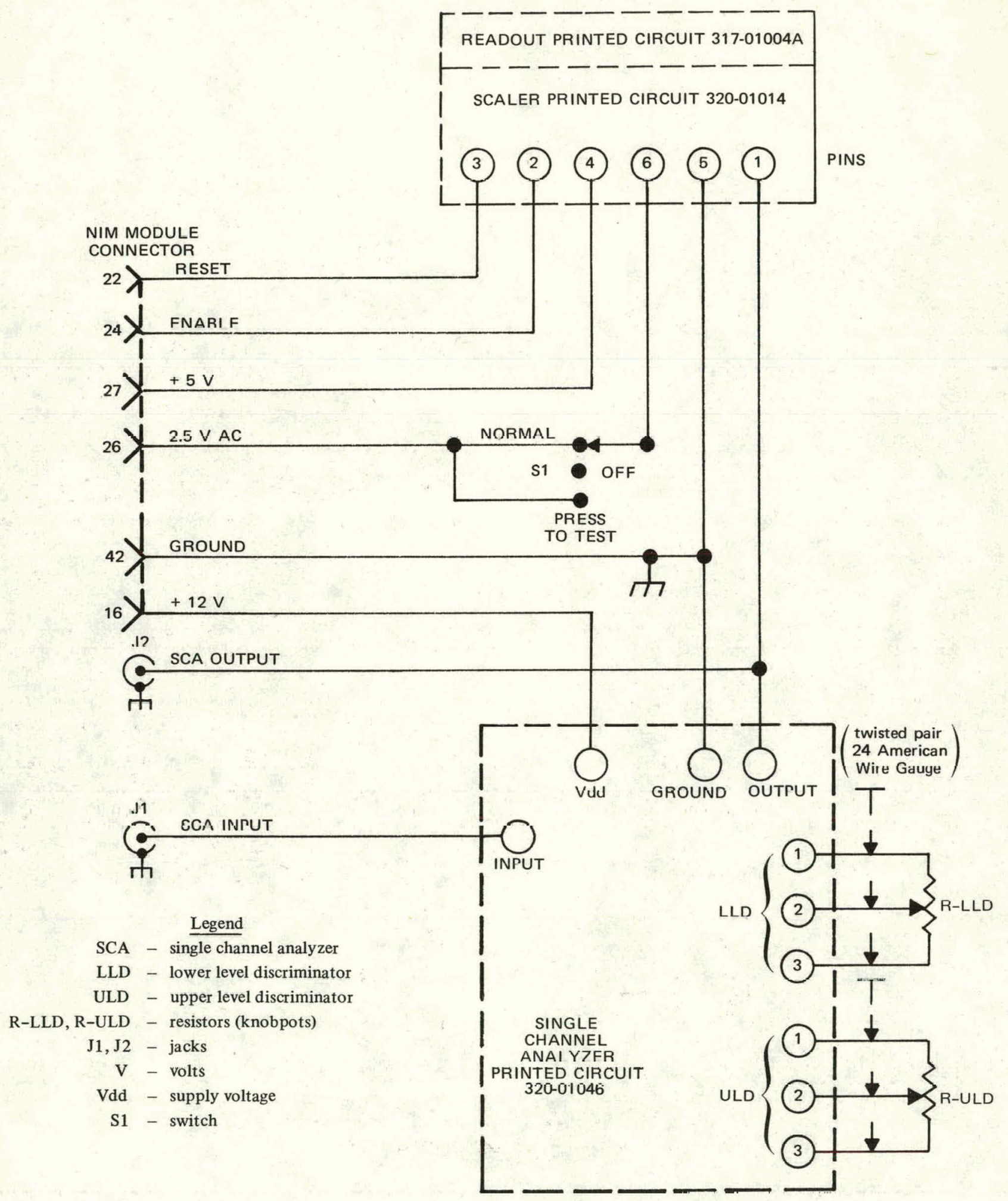

FIGURE 4. Block Diagram of Single Channel Analyzer Scaler Module. 


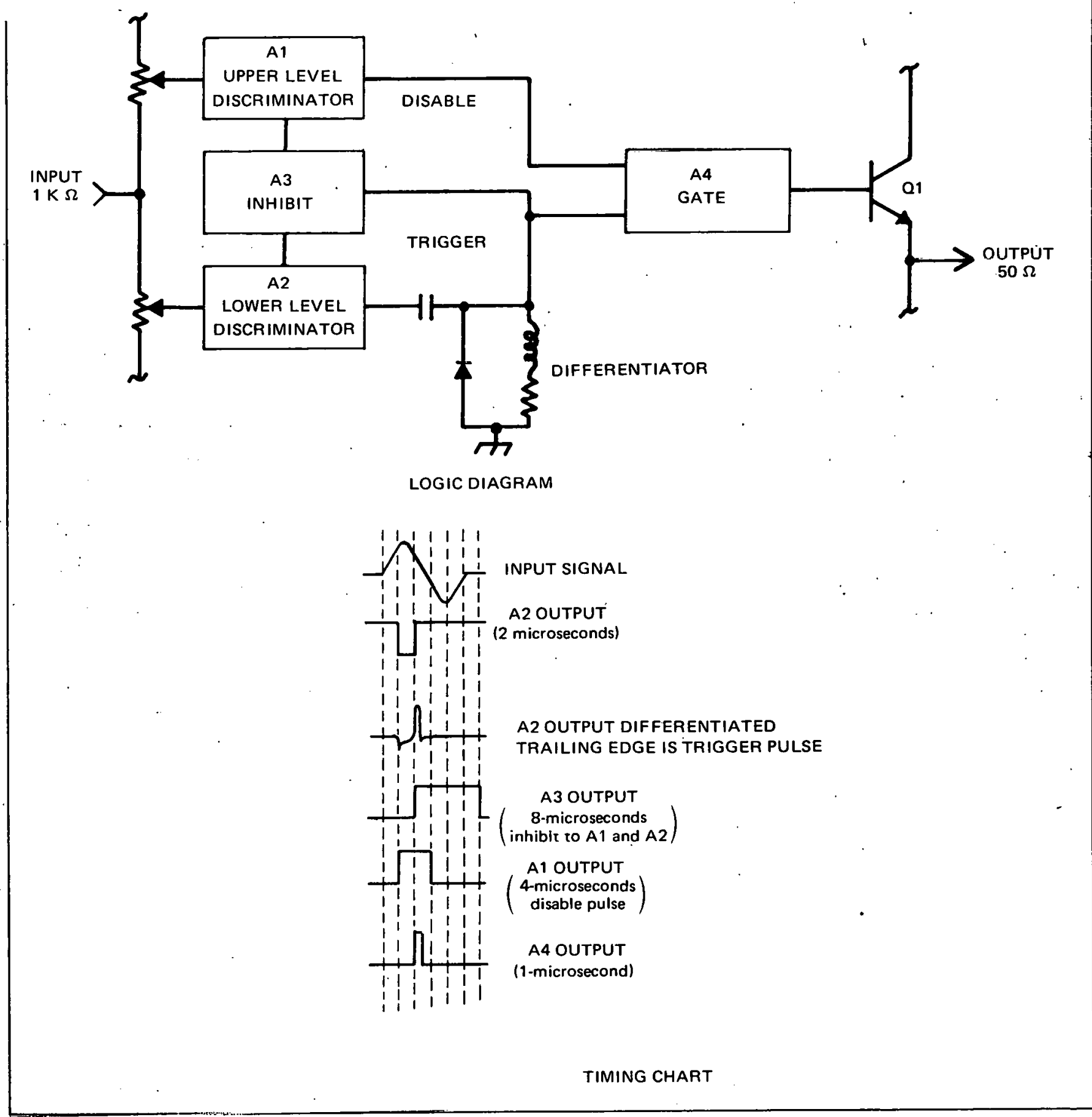

$$
\begin{gathered}
\frac{\text { Legend }}{=} \\
Q 1-\text { transistor } \\
\Omega-\text { ohms }(K=1000)
\end{gathered}
$$

FIGURE 5. Logic Diagram (a) and Timing Chart (b) for Analyzer. 


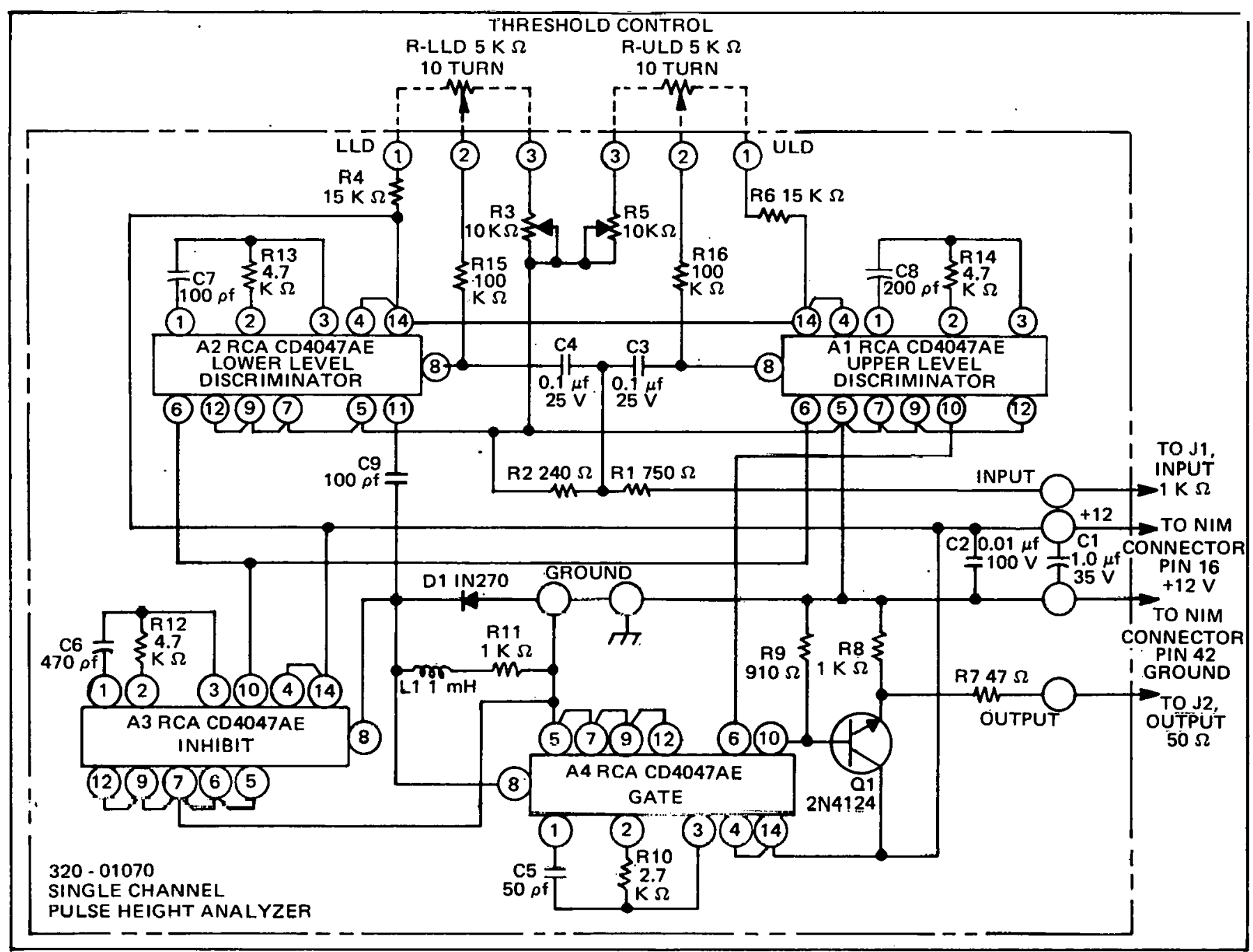

\section{Legend}

R-ULD, R-LLD - knobpotentiometers

R3, R5 - trimpotentiometers

$\mathrm{R} 1, \mathrm{R} 2, \mathrm{R} 4$ and

R6 . . R15 - resistors in ohms $(\Omega)$

$(\mathrm{K}=1000)$

$\mathrm{Cl}$. . C 9 - capacitors [(values as noted in Inicrofarads $(\mu \mathrm{f})$ or picofarads (pf)]

Q1 - transistor

D1 - diode

L1 - coil [i millihenry $(\mathrm{mH})]$

LLD - lower level discriminator

ULD - upper level discriminator .

J1, J2 - jacks

$\mathrm{V}$ - volts

Vdd, Vss - power supply connections

FIGURE 6. Schematic of Printed Circuit Board for Analyzer. 


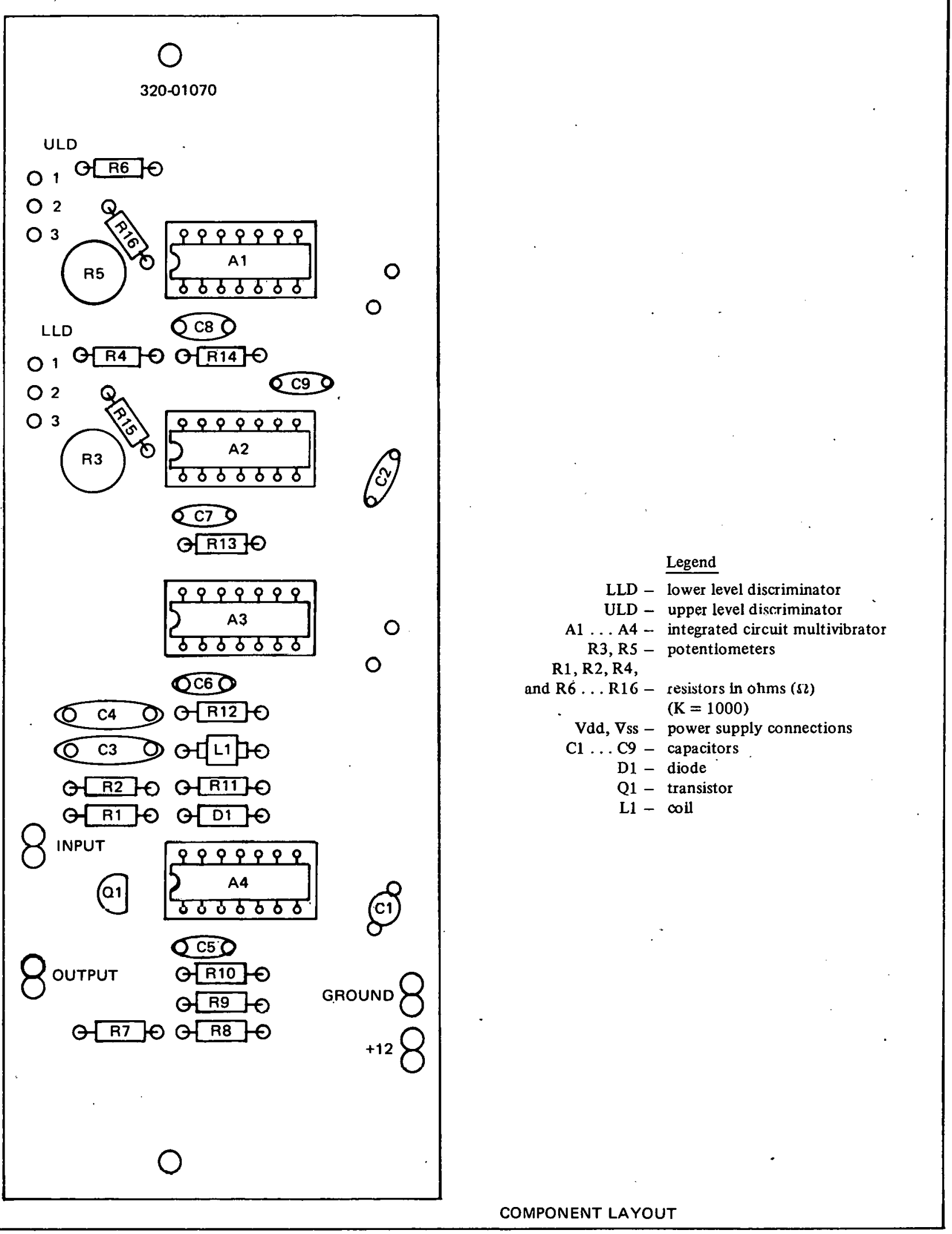

FIGURE 7. Component Layout for Analyzer. 


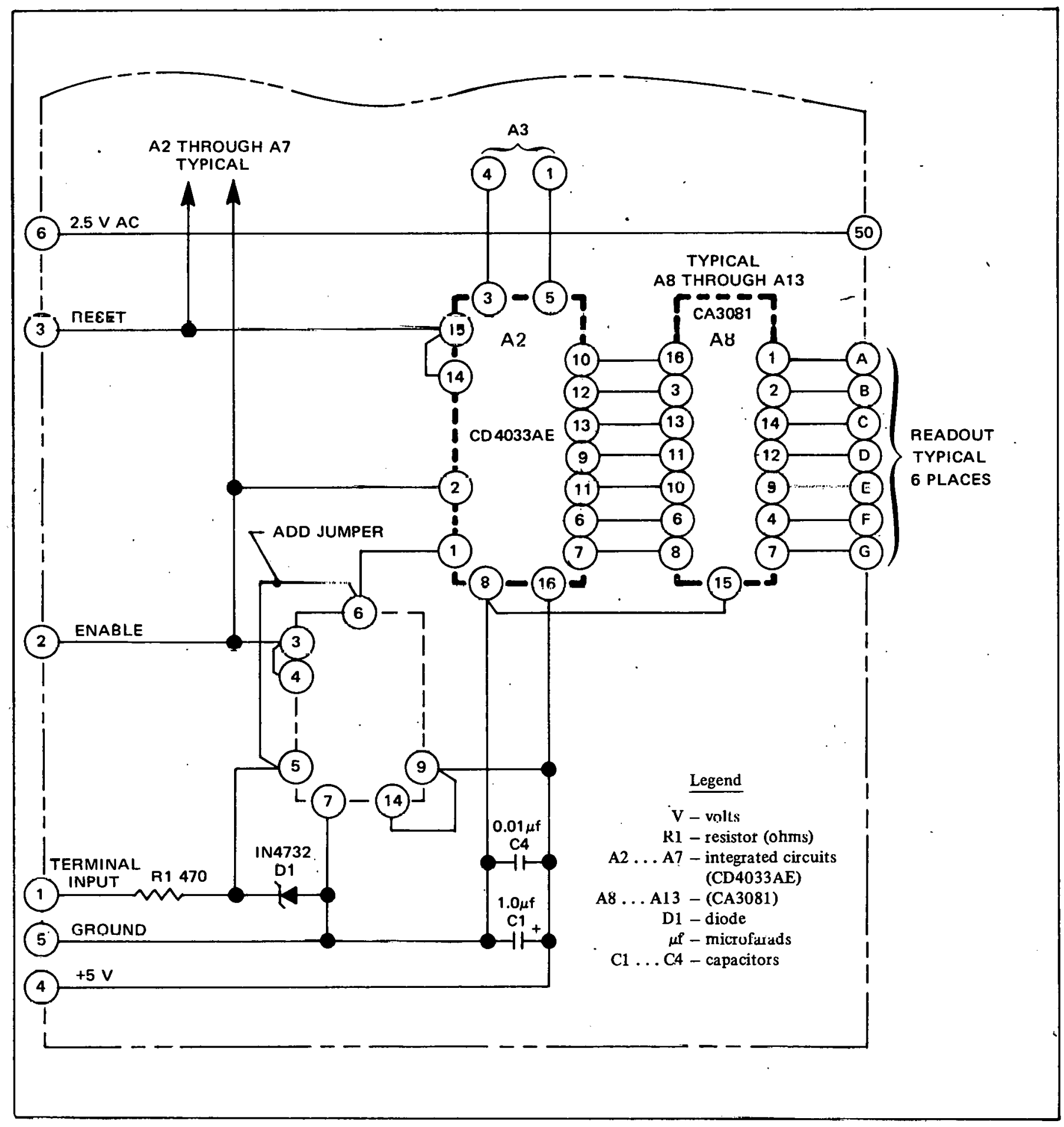

FIGURE 8. Schematic of the Scaler Printed Circuit Board. 


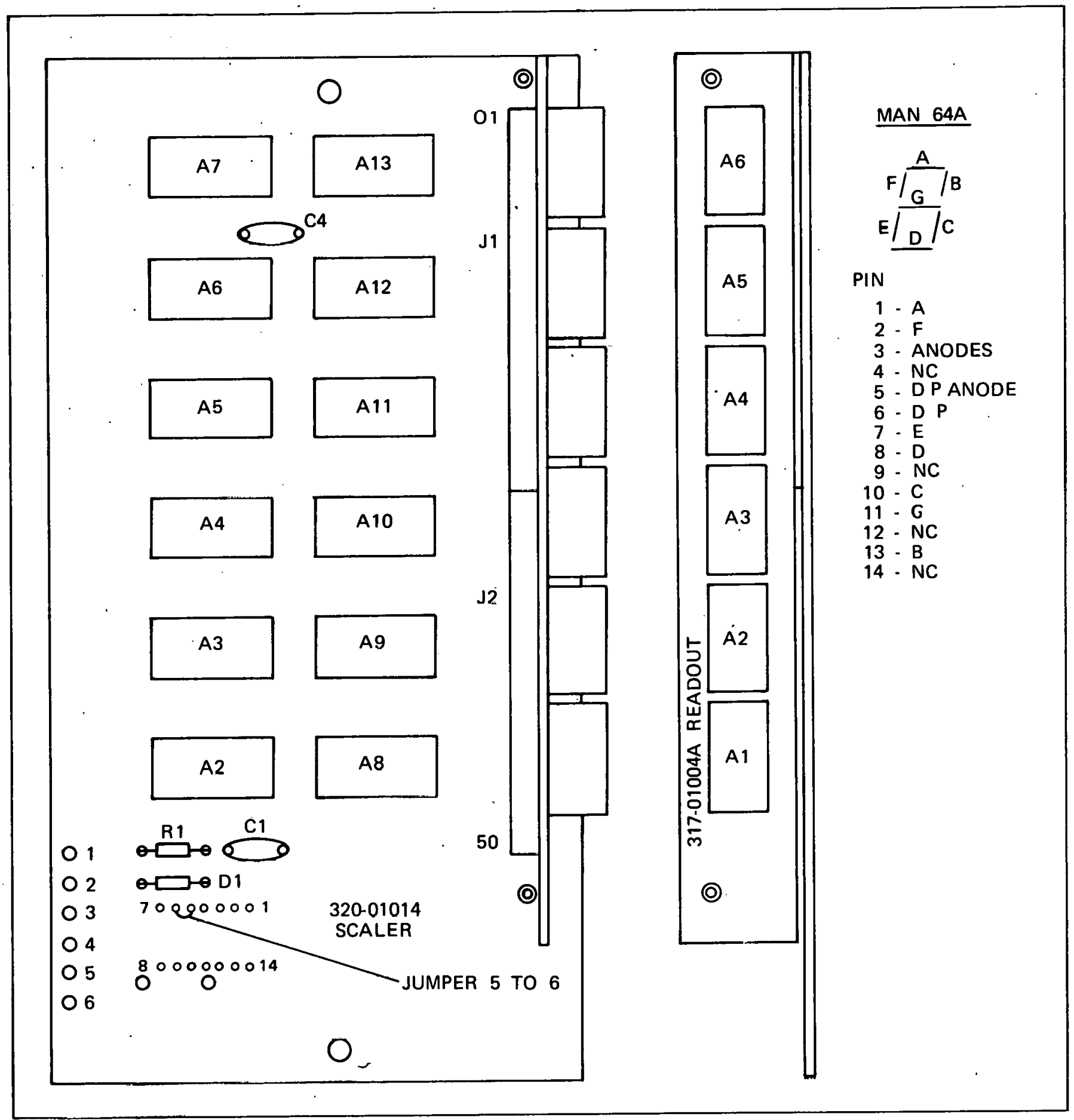

FIGURE 9. Component Layout for Scaler and Readout Printed Circuit Boards. 
RFP-2304 